\title{
Validation of a low-cost wireless sensors node for museum environmental monitoring
}

\author{
Livio D’Alvia ${ }^{1}$, Eduardo Palermo ${ }^{1}$, Stefano Rossi ${ }^{2}$, Zaccaria Del Prete ${ }^{1}$ \\ ${ }^{1}$ Department of Mechanical and Aerospace Engineering, 'Sapienza' University of Rome, via Eudossiana, 18, Roma 00184, Italy \\ ${ }^{2}$ Department of Economics and Management, Industrial Engineering, University of Tuscia, Viterbo, Italy
}

\begin{abstract}
Wireless Sensor Network (WSN) has been adopted in many contexts, such as healthcare or industry. In museum scenarios, WSN has been introduced for environmental monitoring, to control temperature and relative humidity. Nowadays, the development of low-cost micro-scale sensing units, opened to new possibilities for WSN development, enlarging the set of feasible measurements to gaseous pollutant concentration, relative humidity, temperature, light intensity, air flow, or vibration.

This work is part of the overarching goal of developing a low-cost and minimally invasive WSN designed for a museum scenario. The proposed WSN node, based on a ZigBee standard, gathers signals provided by: a 9-axis MIMU, a sensor for temperature and relative humidity, and three gas detection boards. In this paper, specifically, we present performances of the WSN node in detecting: structure tilt, vibrations, and daily cycle of humidity, temperature, and gas deposition.
\end{abstract}

\section{Section: RESEARCH PAPER}

Keywords: sensors; ICT; wireless sensor network; environmental measurement; museum air quality

Citation: Livio D’Alvia, Eduardo Palermo, Stefano Rossi, Zaccaria Del Prete, Validation of a low-cost wireless sensors node for museum environmental monitoring, Acta IMEKO, vol. 6, no. 3, article 7, September 2017, identifier: IMEKO-ACTA-06 (2017)-03-07

Section Editor: Sabrina Grassini, Politecnico di Torino, Italy

Received March 14, 2017; In final form July 29, 2017; Published September 2017

Copyright: (C) 2017 IMEKO. This is an open-access article distributed under the terms of the Creative Commons Attribution 3.0 License, which permits unrestricted use, distribution, and reproduction in any medium, provided the original author and source are credited

Funding: PhD student grant of Sapienza University supported this work

Corresponding author: Livio D’Alvia, e-mail: livio.dalvia@uniroma1.it

\section{INTRODUCTION}

Degrading effects of manufactures in cultural heritage can be classified in: morphological, physical-mechanical, physicalchemical, and optical alterations.

Morphological alterations can involve: dimensional variation (i.e. expansion, torsion, etc.), loss of material and continuity (holes and cracks). Physical-mechanical alterations determine a decrease of cohesion, adhesion, and elasticity. Physical-chemical alterations cause a variation of porosity, hydrophilic and hydrophobic characteristic, etc. Optical alterations influence visual parameters, such as colour, luminosity, etc.

In indoor conservation, all these degrading effects are mostly driven by: (i) relative humidity and temperature; (ii) gaseous pollutants $\left(\mathrm{O}_{3}, \mathrm{SO}_{\mathrm{x}}, \mathrm{NO}_{\mathrm{x}}, \mathrm{CO}_{\mathrm{x}}, \mathrm{H}_{2} \mathrm{~S}, \mathrm{NH}_{3}, \mathrm{HCl}\right.$, etc. $)$ and particulate matter; (iii) light intensity; (iv) air velocity and direction; (v) sound pressure and vibration [1]-[3].

Environmental parameters monitoring is necessary to preserve materials, to identify causes of degradation, and to quantify their effects, as a function of time [4], [5]. However, the development of a fully inclusive and compact solution to precisely and punctually identify the effects induced by environmental- and anthropic-related factors is still an open challenge [6]. Commercial solutions and wireless devices are cumbersome, bulky, and not-aesthetic when placed next to artefacts, and expensive.

Currently Wireless Sensor Networks (WSN) have been employed in several application fields as in indoor/outdoor environmental monitoring or gas detection, both in healthcare and industrial contest [7]-[9].

Application of WSN in a museum scenario has been so far restricted to the monitoring of temperature and relative humidity [10], [11]. The deployment of a WSN monitoring system presents valuable pros, such as: architecture scalability, the capability to integrate multiple and heterogeneous sensors on a single small node, the possibility to distribute a high 
number of wireless and low-cost measurement points in the exhibition areas.

We decided to develop a novel, low-cost, wireless, scalable system, capable to control environmental parameters, as well as vibrations and deformation, temperature and humidity, gaseous pollutant, over a multi-stage research project, combining MEMS sensor boards and electrochemical-cells. In this paper we present a system that we have developed and validated for: a) detection of tilt and shock and define the frequency limit, b) acquisition of the daily cycle of environmental pollutant.

In Section 2 we will discuss the state of art of heritage monitoring and wireless networks applied in this context and the most significant environmental parameters and their effect. In Section 3 we describe the architecture of our developed WSN node based on the IEEE 802.15.04 and the experimental tests performed to validate the system. Results of the research are presented and discussed in Section 4. Finally, in the concluding section, the major achievements are summarized.

\section{STATE OF ART}

Despite internal environmental parameters play an important role in the museums conservation, the monitoring activity has not benefited substantially of recent technological developments [12], [13]. Several studies proposed limited solutions to evaluate the quality of expositive habitat, focusing especially on temperature and humidity measurements, and, sometimes, on gaseous pollutant, through a passive/diffusive traditional sampler.

Some authors [14]-[20] highlighted the importance of investigating the fluctuation of air temperature $(\mathrm{T})$ and percentage relative humidity $(\% \mathrm{RH})$, identifying these parameters as determinant in the deterioration of collected artefacts.

At the same time, they pointed out the difficulty to install sparse measurement stations preserving artworks appearance. In fact, many museums, art galleries and historical buildings in general are themselves masterpieces, making the installation of bulky monitoring devices inappropriate.

In addition to temperature and relative humidity, several works [16], [21]-[27] presented methodologies to sample the Inorganic or Volatile Organic Compounds $\left(\mathrm{NO}_{\mathrm{x}}, \mathrm{O}_{3}, \mathrm{SO}_{\mathrm{x}}\right.$, VOC) and particulate matter. The first quantities are sampled through chemisorbing cartridges that require a subsequent analysis with ultraviolet-visible (UV-VIS) spectrophotometry or ion chromatography. For particulate matter, controlled flow ratio samplers with filters that permit a detailed analysis of elemental concentrations with SEM microscopy are used.

All these analyses cannot be performed in ordinary survey due to excessive costs of equipment and post-process analysis. Moreover, only the thermo-hygrometric analysis can be associated to a remote wireless network, while the other techniques require the intervention of specialized technicians/analysts.

Saraga et al. [25] discussed the application of measurement units for external environmental monitoring, including: (i) ultraviolet photometry automatic analyzers for $\mathrm{O}_{3}$ (EN 14625:05); (ii) ultraviolet fluorescence for $\mathrm{SO}_{2}$ (EN 14212:05); (iii) chemiluminescence for $\mathrm{NO}_{\mathrm{x}}$ (EN 14211:05), and (iv) gravimetric measurement for $\mathrm{PM}_{10}\left(\mathrm{EN}\right.$ 12341:99) and $\mathrm{PM}_{2.5}$ (EN 14907:05). The proposed instrumentation has a dimension of $42.5 \mathrm{~cm}(\mathrm{~W}), 157.5 \mathrm{~cm}(\mathrm{H}), 58.5 \mathrm{~cm}(\mathrm{D})$, occupying a volume that could be incompatible with museum applications and a total cost around $10.000 €$.

The indoor, low-cost, small scale solution we are developing is inspired to what is proposed by Mead et Al. [28] for external monitoring. They integrated in a single board: (i) an environmental parameter sensor (temperature, relative humidity, barometric pressure); (ii) an electrochemical cell to monitor gas pollutant; (iii) one optical particles counter (OPC) to control the total particle matter; and (iv) an anemometer to analyze the wind direction and intensity, showing the real benefits related to low-cost sensing. Building on their findings, here we propose a solution cut off for including indoor functionality, integrating inertial data to the environmental ones. Such an effort completes the solutions proposed by [10], [11], where an Original Equipment Manufacturer (OEM)-WSN has been proposed, to monitor only temperature and humidity into a museum environment.

E. Angelini et al. [29] proposed a Smart sensors board for microclimate monitoring; Corbellini et al. [30] introduced a sensor network architecture developed for museum monitoring and F. Diego et Al. [31] propose a sensor network architecture to read physical parameters in the cultural heritage field. The aim of these works was mainly focused on the variation of temperature and relative humidity in a museum.

In this research, we seek to integrate in a single board two MEMS sensors: one for tilt and vibration detection and one for environmental parameter (temperature and relative humidity) monitoring. In addition, three electrochemical cells are used to monitor pollutant concentrations. Current cost is $500 €$ for the whole system with a dimension of $9.5 \mathrm{~cm}(\mathrm{~W}), 16.0 \mathrm{~cm}(\mathrm{H}), 6.0$ $\mathrm{cm}$ (D).

\section{MATERIALS AND METHODS}

\subsection{Prototype description}

The $\alpha$-device of the WSN node is composed by a transmitting/receiving ZigBee unit, a computational unit based on a RISC Microcontroller AVR ATmega328P, and two development-boards with MEMS sensor units: (i) a Bosh BMO055 9-axis MIMU (Magnetic Inertial Measurement Unit), (ii) a Bosh BNE280 humidity, pressure, and temperature sensor, and an Alphasense 3 input analogic front-end sensor board for $\mathrm{NO}, \mathrm{NO}_{2}$ and $\mathrm{SO}_{2}$ concentrations, as reported by the schematic in Figure 1. All sensors are connected to the

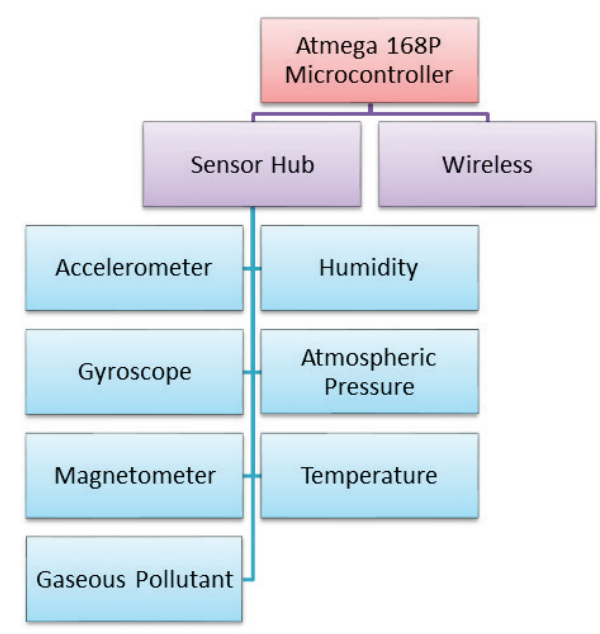

Figure 1. Architecture of the proposed WSN with microcontroller and analysed parameter. 
microcontroller via an i2c serial communication bus.

Figure 2 shows the real prototype with highlighted the constituent block: (a) Control Unit, (b) Power Supply, (c) Radio Modules and (d) Sensors Unit plug-in.

a) Control Unit

The proposed wireless node is based on a Microcontroller (MCU) ATmega328P, a low power microcontroller with two SPI serial interfaces, one programmable serial USART (used to interface the MCU with an external PC for programming) and other serial devices (e.g. Radio device) and a TWI serial bus used to communicate with the MEMS Sensor Board (encircled in black).

b) Power Supply

The Radio Modules and Sensor Board require a stable $3.3 \mathrm{~V}$ source and a MCU at a $5 \mathrm{~V}$ source. A LT7805 regulates the input voltage $(5-38 \mathrm{~V})$ to a $5 \mathrm{~V}$ output with standard deviation lower than $35 \mathrm{mV}$ and a LD33 tension regulator converts $5 \mathrm{~V}$ to $3.3 \mathrm{~V}$ (cyan blue box).

c) Radio Module

The Radio Module is a transmitting/receiving ZigBee unit IEEE 802.15 .4 in $2.4 \mathrm{GHz}$ band with $+3 \mathrm{~dB}$ output power and $250 \mathrm{kbit} / \mathrm{s}$ transmission. It is used in AT commands directly connected to the USART of the ATmega328P (grey box).

d) Plug-in for Sensor Boards

The BNO055 (highlighted in red) is a low-cost MEMS System in Package (SiP) that integrates a 3-axis 14-bit accelerometer, a 3-axis 16-bit gyro, a 3-axis geomagnetic sensor and a 32-bit cortex $\mathrm{M} 0+$ microcontroller for the data sensor fusion (quaternion and Euler angles) [32]. The possibility for the experimenter to set-up the acceleration ranges and the lowpass filter bandwidths, permits to adapt the sensor to several applications such as the museum scenario where the vibrations are induced by visitors or a Heating, Ventilation and Air Conditioning (HVAC) system.

The BME280 (encircled in green) is a low-cost MEMS SiP that combines a digital humidity, a pressure sensor, and a temperature sensor.

The Alphasense 3-AFE 810-0019-03 model sensor board (circled in orange) is an analog front-end board integrating three different electrochemical cells. The board is a current $(\mathrm{nA})$ to voltage $(\mathrm{mV})$ converter. The current represents the output of the sensors and it is given by the reduction/oxidation of the pollutant due the electrolyte reservoir inside the electrochemical cell that generates a flow of electrons. The

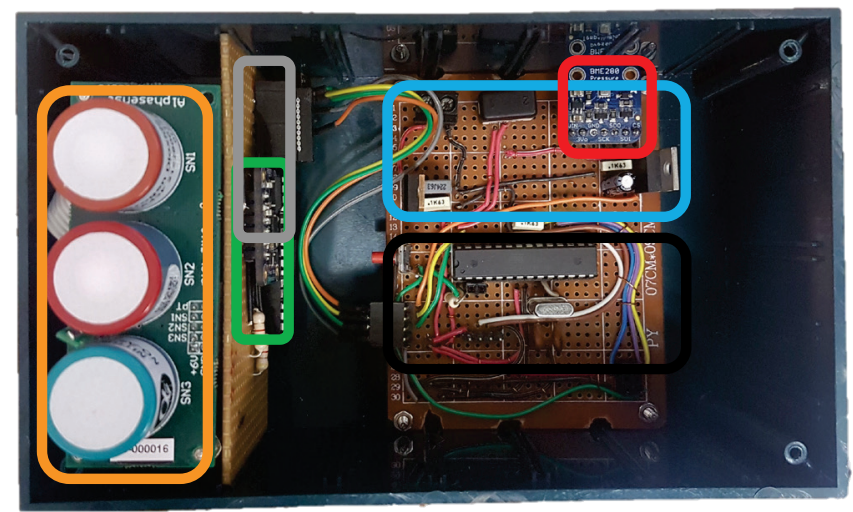

Figure 2. $\alpha$-device PCB with microcontroller boxed in black, power supply in cyan, ZigBee in grey, and BNO055, BME280 and Electrochemical cell respectively in red, green and orange box. support circuit in addition provides a low noise power supply voltage and a bias compensation signal specific for each gas sensor.

The implemented sensors are: a NO-A4 for Nitric Oxide and a sensitivity of $0.342 \mathrm{mV} / \mathrm{ppb}$ [33], a $\mathrm{NO}_{2}-\mathrm{A} 43 \mathrm{~F}$ for Nitrogen Dioxide with a range of 0 to $20 \mathrm{ppm}$ and a sensitivity of $0.197 \mathrm{mV} / \mathrm{ppb}$ [34], a $\mathrm{SO}_{2}$-A4 Sulphur Dioxide with a range of 0 to $50 \mathrm{ppm}$ [35], where ppm and ppb mean respectively part per million and part per billion. All sensors are chosen according to the OMS guidelines [36] that indicate the maximum level for the pollution.

The system is calibrated and certified by the producer to give to the user information needed to compensate both zero and sensitivity drift for each sensor.

\subsection{Experimental procedure}

The MIMU sensor is employed for two monitoring activities: (a) tilt detection of wall due to fracture and/or deformation, and (b) shock detection. To assess the performance of the MIMU in these two applications, two experimental setups have been designed: (i) the former including a rotating plate and (ii) the latter including an electrodynamic shaker.

In our node prototype, tilt and shock will be detected by different processing data from the same inertial sensor. For this reason we set a cut-off frequency for the in-built settable lowpass filter at $250 \mathrm{~Hz}$, a high value for tilt but required for properly acquiring vibrations.

The environmental sensors, for hydrothermal values and pollutant concentration, have been placed outdoor, for evaluating the system in proximity of a certified pollution monitoring system by ARPA Lazio (Lat. $41.864194^{\circ}$, Lon. $\left.12.469531^{\circ}\right)$.

\subsubsection{Tilt detection}

A servomotor controlled in closed loop by means of an angular encoder (Sanmotion rs1a03aa) has been used to estimate the accuracy and the stability of the embedded accelerometers. Specifically, the MIMU was mounted on a vertical plate connected to the servomotor through a belt as shown in Figure 3.

The BNO055 has been programmed by setting the internal low-pass second order filter to $2501 \mathrm{~Hz}$ and the measurement range to $\pm 16 \mathrm{~g}$ (same parameters were selected for vibration detection test).

A LabVIEW program has been implemented to rotate the plate around the horizontal axis from $0^{\circ}$ to $180^{\circ}$ with a step of

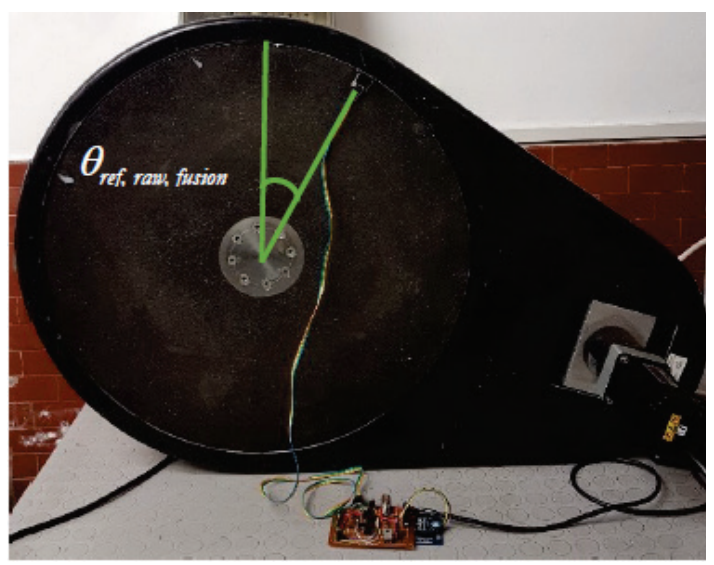

Figure 3. Plate with highlighted the $\theta_{\text {raw }}, \theta_{\text {fusion, }} \theta_{\text {ref }}$ angles. 
$1^{\circ}$ every 15 minutes, simulating tilt rotations induced by structural deformations. We acquired tilt angles measured by the encoder $\left(\theta_{r e f}\right)$, the roll angle $\left(\theta_{\text {ran }}\right)$ calculated directly by three acceleration components $\left(\boldsymbol{a}_{\boldsymbol{x}}, \boldsymbol{a}_{\boldsymbol{y}}, \boldsymbol{a}_{\boldsymbol{z}}\right)$, and the roll angle provided by the data fusion algorithm that is embedded into the sensor $\left(\theta_{\text {fusion }}\right)$.

To validate the built-in sensor fusion algorithm, the accuracy of the accelerometers was estimated by means of the Root Mean Square Error (RMSE) between the average values of the measured signals $\left(\theta_{\text {ram }}, \theta_{\text {fusion }}\right)$ in the 15 minutes' window, and each reference angle $\left(\theta_{r e f}\right)$, gathered every 15 minutes. The standard deviation of $\theta_{\text {raw }}$ was evaluated to estimate the noise of the accelerometers, an important parameter to avoid misdetection, due to long-term functioning of the sensor.

\subsubsection{Shock detection}

A Vibration Exciter Type 4809 (Bruel\&Kejar) has been used to provide known inputs to the sensor. We compared the output of the filtered (at $250 \mathrm{~Hz}$ cut-off frequency) MIMU output with a reference signal provided by a certified monoaxial accelerometer (Bruel\&Kejar 4371 model.) Both sensors have been placed on top of the Vibration Exciter as shown in Figure 4 . The test has been repeated for 8 different oscillation frequencies in the range $10-50 \mathrm{~Hz}$ with a $5 \mathrm{~Hz}$ step. This range of frequencies has been chosen to respect the Nyquist condition, as the maximum sampling frequency in this prototype is limited by the USART transmission time of $9 \mathrm{~ms}$. However, the selected range is compatible with other studies in the field [37]-[39]. A high accuracy waveform generator has imposed the sinusoidal motion, with a fixed peak-to-peak displacement amplitude $(0.5 \mathrm{~mm})$ for all frequencies. The described procedure has been repeated three times, by aligning each time a different MIMU axis with the motion axis. Accuracy has been evaluated by calculating the RMSE between test and reference signals, normalized to the peak-to-peak value of the reference sensor (nRMSE).

\subsubsection{Environmental parameter}

In the preliminary test, we decided to put the sensor system outdoor, in proximity of a certified monitoring system (ARPA), during a five-days acquisition. To evaluate the accuracy of the sensor output in mutable meteorological and traffic conditions the system has been programmed with a sample period of 1 minute. The acquired data have been post-processed by calculating the moving averages of the outputs, with a one-hour step and an 8-hours window (8h-Avarage).

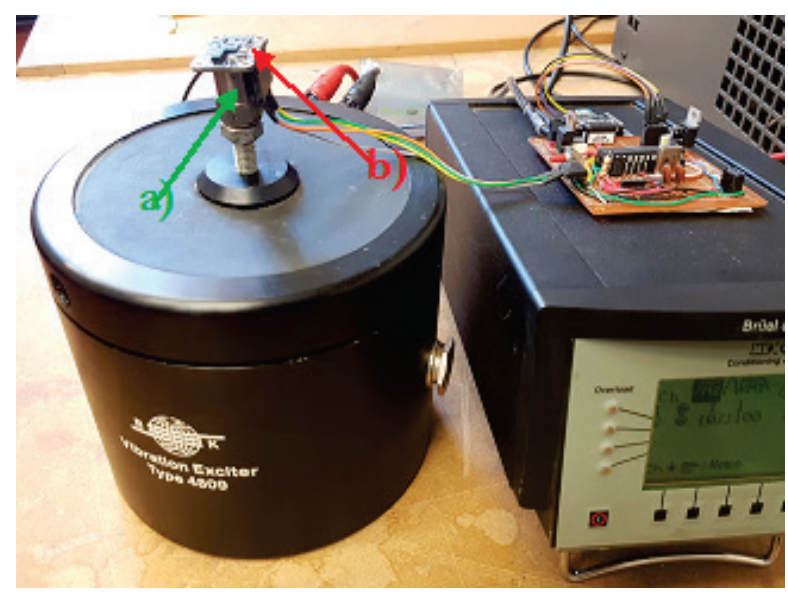

Figure 4. Vibration Exciter whit reference sensor (a) and MIMU (b).
Regarding gas concentrations, the temperature dependence is corrected in post-processing using the output of the embedded Pt1000. Corrected gas concentration values are calculated using the formula provided by the calibration certificate

\section{RESULTS AND DISCUSSIONS}

\subsection{Tilt Detection}

The relation between $\theta_{\text {ref }}$ and $\theta_{\text {raw }}$ is shown in Figure 5. The MIMU accuracy for this measurement, evaluated though the RMSE was equal to $0.3^{\circ}$. The SD of the MIMU output was always lower than $0.4^{\circ}$ in the $0-180^{\circ}$ tilt range.

Figure 5 reports the test results in the $0-90^{\circ}$ range. The RMSE between $\theta_{\text {fusion }}$ and $\theta_{\text {ref }}$ was equal to $0.2^{\circ}$ and the SD was always lower than $0.2^{\circ}$ in the $0^{\circ}-180^{\circ}$ tilt range.

This wide range was chosen to assess accuracy in the tilt angle measurement regardless of initial placement of the sensor, since MEMS accelerometers embedded into MIMUs can present different accuracy levels for each axis.

Figure 6 shows the comparison between $\theta_{\text {raw }}$ and the one provided by the internal sensor fusion algorithm $\theta_{\text {fusion }}$. Figure 6 highlights how the fusion algorithm output is less sensible to noise and, consequently, more stable over time, with a maximum SD of $0.2^{\circ}$. The embedded data fusion algorithm, based on a Kalman filter, can filter noise; however, due to the slow dynamics of the phenomenon, the increased stability is not paid in terms of noise, as demonstrated by the RMSE.

\subsection{Results of Shock Detection}

Figure 7 shows the comparison between $\boldsymbol{a}_{r e f}$ and $\boldsymbol{a}_{y}^{\text {test }}$, in correspondence of an excitation frequency equal to $20 \mathrm{~Hz}$. Figure 8 highlights the nRMSE for the three axes over the entire excitation frequency range. From the analysis of both figures it clearly appears that phase shift between the

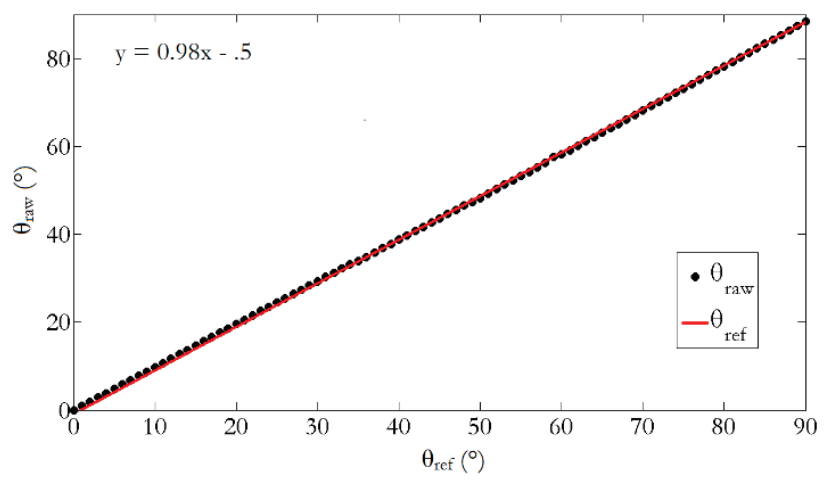

Figure 5. Relation between $\theta_{\text {raw }}$ and $\theta_{\text {ref }}$ between 0-90 .

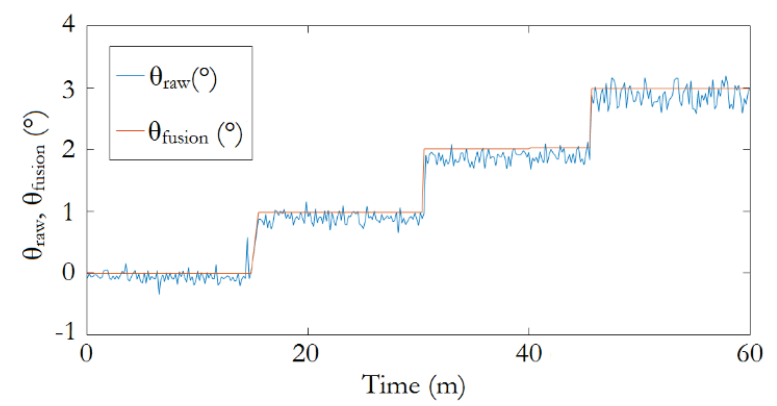

Figure 6. Comparison between $\theta_{\text {raw }}$ and $\theta_{\text {fusion }}$ in $0-3^{\circ}$ 


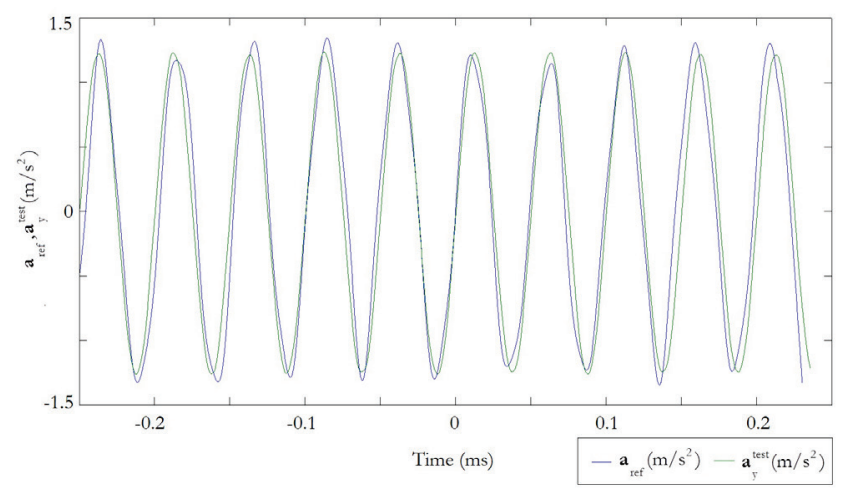

Figure 7. Example of acceleration signals acquired via the two systems.

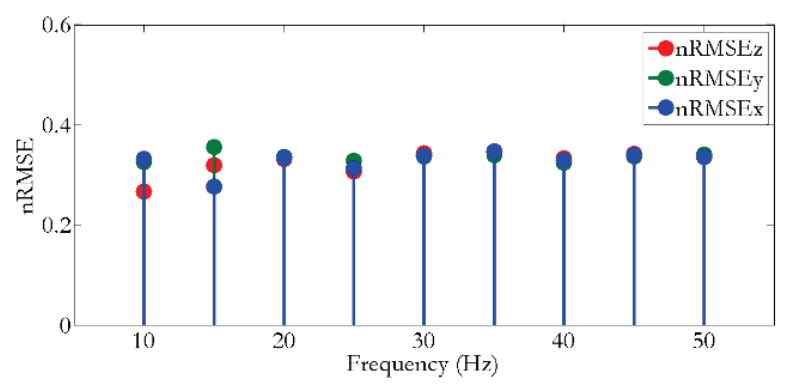

Figure 8. Normalized RMSE (nRMSE) for all axis and frequencies.

acceleration measured through the MIMU and the one measured with the certified accelerometer is negligible, despite the difference in signal filtering. MIMU uses an internal second order low pass filter, with undeclared parameters, while to the certified accelerometer signal we applied a second order Butterworth digital filter, with a $250 \mathrm{~Hz}$ cut-off frequency.

The nRMSE value was similar for the three axes, with a mean value of 0.35 for the $x$ and $z$ axis, and of 0.36 for the $y$ axis.

\subsection{Environmental and pollution detection}

Figure 9 reports the outdoor concentration of pollutant gasses in $\mathrm{ppb}$ in two chosen days, between 12:00 AM of Friday 02/10/17 to 12:00 AM of Sunday 02/12/17. In general, the pollutant gasses concentration is lower during the night than during daytime. Values are compatible with the concentration values provided by the certified system [40], [41] and lower than the normalized day limits (140 ppb for $\mathrm{SO}_{2}, 100 \mathrm{ppb}$ for $\mathrm{NO}_{2}$ and $\mathrm{NO}$ ). The Arpa System reported a maximum of $\mathrm{NO}_{2}$ hourly concentration at 7pm for both 10 and 11 February 2017. These peak timings correspond with the ones in Figure 8, even

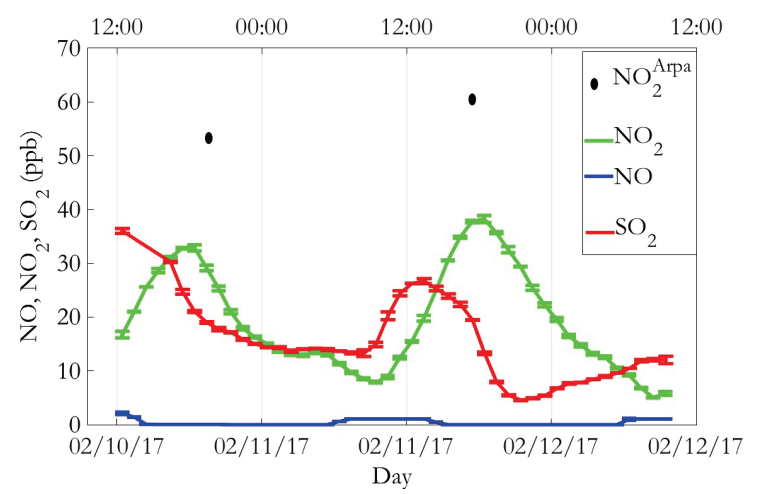

Figure 9. 8h-average gas concentration for $\mathrm{SO} 2, \mathrm{NO} 2$, NO with 8h-SD. if the actual value measured with our WSN (37 ppb against 60 ppb from ARPA system) is affected by the height difference.

The maximum level of $\mathrm{SO}_{2}$ concentration appears to be $1 \mathrm{pm} . \mathrm{SO}_{2}$ is an impurity compound of fossil fuel commonly used in buildings.

The highest values of hourly SD were $0.7 \mathrm{ppb}$ for $\mathrm{NO}_{2}, 0.2$ ppb for $\mathrm{NO}, 0.8 \mathrm{ppb}$ for $\mathrm{SO}_{2}$.

Figure 10 shows the day-night cycle of temperature and $\mathrm{RH}$ in the two chosen days, between 12:00 AM of Friday 02/10/17 to $12: 00 \mathrm{AM}$ of Sunday $02 / 12 / 17$. As expected, the sensor shows an evident decrease in $\mathrm{RH}$, in correspondence to an increase in temperature (ex. $12 \mathrm{am}$ ). Maximum values of SD were $0.4{ }^{\circ} \mathrm{C}$ and $0.6 \%$ for temperature and relative humidity, respectively.

\section{CONCLUSIONS}

We designed and analysed the performances of a low cost wireless sensor network node for the environmental monitoring of cultural heritage. At this stage of development, we focused on the assessment of the accuracy and stability of tilt angle and shock detection, measurement of gass concentration and thermo-hygrometric parameters.

The tilt measurement demonstrated a good accuracy for the targeted application. The observed stability was more than acceptable, demonstrating the robustness of the solution as a function of time. The embedded data fusion algorithm demonstrated a good capability of filtering noise without losing responsiveness for this application.

Shock vibration detection demonstrated a stable behaviour over the chosen frequency range $(10-50 \mathrm{~Hz})$, along the three different axes. Figure 8 shows not negligible nRMSE values (35 $\%$ ) for frequencies over $20 \mathrm{~Hz}$, but they can be considered acceptable for the shock detection purpose.

Outdoor behaviour confirmed the expected inverse proportionality between temperature and $\mathrm{RH}$.

Gas concentration sensors showed a trend over time comparable to data from the ARPA system, with a time correspondence in peak values, even if a difference in average values was observable, due to a different height positioning (Figure 9).

Despite the wide operating range ( 0 to $20 \mathrm{ppm}$ ) of the gas sensors, in general gas concentrations at street level are in the range of 20-200 ppb for $\mathrm{SO}_{\mathrm{X}}$ and $\mathrm{NO}_{\mathrm{X}}$, according to the OMS guideline. Values found in this study are in line with expectations.

Alphasense's electrochemical cells present limitation due to cross sensitivity to other chemical compounds, life time (2 years) and drift. However, the limited cost (ca. $50 €$ each) allows for a large diffusion of sensor's nodes in a limited area.

The $\beta$-device of the WSN will integrate light sensors and other pollutant sensors, such as $\mathrm{CO}_{2}$, to provide a complete

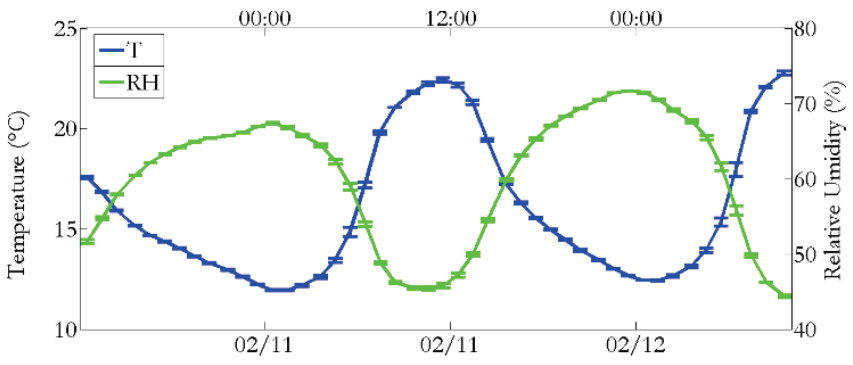

Figure 10.8 h-average for temperature and relative humidity with SD. 
description of the environmental parameters of interest in a museum scenario. In addition, a finest firmware will be implemented on the device, and a data buffer will be added to overcome the communication timing jitter and extend the shock detection frequency range.

\section{ACKNOWLEDGEMENT}

The Authors would like to acknowledge prof. Paolo Cappa, who passed away on August, 26th 2016. His contribution was fundamental for planning the work. His tireless effort along with his precious suggestions led the team to a remarkable professional growth.

\section{REFERENCES}

[1] G. Pavlogeorgatos, "Environmental parameters in museums," Build. Environ., vol. 38, no. 12, pp. 1457-1462, Dec. 2003.

[2] P. Brimblecombe, "The composition of museum atmospheres," Atmos. Environ. Part B. Urban Atmos., vol. 24, no. 1, pp. 1-8, Jan. 1990.

[3] R. Hamilton and H. Crabbe, "Environment, Pollution and Effects," in The Effects of Air Pollution on Cultural Heritage, 1st ed., R. Hamilton, V. Kucera, J. Tidblad, and J. Watt, Eds. Boston, MA: Springer US, 2009, pp. 1-27.

[4] F. J. García-Diego and M. Zarzo, "Microclimate monitoring by multivariate statistical control: The renaissance frescoes of the Cathedral of Valencia (Spain)," J. Cult. Herit., vol. 11, no. 3, pp. 339-344, 2010.

[5] M. F. Mecklenburg and C. S. Tumosa, "Temperature and Relative Humidity Effects on the Mechanical and Chemical Stability of Collections," Ashrae, vol. 41, no. 4, pp. 69-74, 1999.

[6] N. S. Baer and P. N. Banks, "Indoor air pollution: Effects on cultural and historic materials," Museum Manag. Curatorsh., vol. 4, no. 1, pp. 9-20, Mar. 1985.

[7] V. Jelicic, M. Magno, G. Paci, D. Brunelli, and L. Benini, "Design, characterization and management of a wireless sensor network for smart gas monitoring," in 2011 4th IEEE International Workshop on Advances in Sensors and Interfaces (IW ASI), 2011, vol. 4, pp. 115-120.

[8] K. K. Khedo, R. Perseedoss, and A. Mungur, "A Wireless Sensor Network Air Pollution Monitoring System," Int. J. Wirel. Mob. Networks, vol. 2, no. 2, pp. 31-45, May 2010.

[9] A. Somov, A. Baranov, D. Spirjakin, A. Spirjakin, V. Sleptsov, and R. Passerone, "Deployment and evaluation of a wireless sensor network for methane leak detection," Sensors Actuators, A Phys., vol. 202, pp. 217-225, 2013.

[10] F. Viani, F. Robol, E. Giarola, A. Polo, A. Massa, and A. Toscano, "Wireless monitoring of heterogeneous parameters in complex museum scenario," in 2014 IEEE Conference on Antenna Measurements \& Applications (CAMA), 2014, pp. 1-3.

[11] G. Menduni, F. Viani, F. Robol, E. Giarola, A. Polo, G. Oliveri, P. Rocca, and A. Massa, "A WSN-based architecture for the EMuseum - the experience at 'Sala dei 500' in Palazzo Vecchio (Florence)," in 2013 IEEE Antennas and Propagation Society International Symposium (APSURSI), 2013, pp. 1114-1115.

[12] D. Camuffo, Microclimate for Cultural Heritage, Second. 2014.

[13] J. Ferdyn-Grygierek, "Monitoring of indoor air parameters in large museum exhibition halls with and without air-conditioning systems," Build. Environ., vol. 107, pp. 113-126, Oct. 2016.

[14] F. Sciurpi, C. Carletti, G. Cellai, and L. Pierangioli, "Environmental monitoring and microclimatic control strategies in 'la Specola' museum of Florence," Energy Build., vol. 95, pp. 190-201, 2015.

[15] J. Ferdyn-Grygierek, "Indoor environment quality in the museum building and its effect on heating and cooling demand," Energy Build., vol. 85, pp. 32-44, 2014.

[16] D. Camuffo, "Environmental monitoring in four European museums," Atmos. Environ., vol. 35, no. 1, pp. 127-140, 2001.
[17] D. Camuffo, A. Bernardi, G. Sturaro, and A. Valentino, "The microclimate inside the Pollaiolo and Botticelli rooms in the Uffizi Gallery, Florence," J. Cult. Herit., vol. 3, no. 2, pp. 155161, 2002.

[18] M. La Gennusa, G. Rizzo, G. Scaccianoce, and F. Nicoletti, "Control of indoor environments in heritage buildings: experimental measurements in an old Italian museum and proposal of a methodology," J. Cult. Herit., vol. 6, no. 2, pp. 147155, Apr. 2005.

[19] F. Becherini, A. Bernardi, and E. Frassoldati, "Microclimate inside a semi-confined environment: Valuation of suitability for the conservation of heritage materials," J. Cult. Herit., vol. 11, no. 4, pp. 471-476, 2010.

[20] H. Janssen and J. E. Christensen, "Hygrothermal optimisation of museum storage spaces," Energy Build., vol. 56, pp. 169-178, 2013.

[21] B. Krupinska, A. Worobiec, G. Gatto Rotondo, V. Novaković, V. Kontozova, C.-U. Ro, R. Van Grieken, and K. De Wael, "Assessment of the air quality (NO2, SO2, O3 and particulate matter) in the Plantin-Moretus Museum/Print Room in Antwerp, Belgium, in different seasons of the year," Microchem. J., vol. 102, no. 2, pp. 49-53, 2012.

[22] B. Krupinska, R. Van Grieken, and K. De Wael, "Air quality monitoring in a museum for preventive conservation: Results of a three-year study in the Plantin-Moretus Museum in Antwerp, Belgium," Microchem. J., vol. 110, pp. 350-360, 2013.

[23] R. H. M. Godoi, B. H. B. Carneiro, S. L. Paralovo, V. P. Campos, T. M. Tavares, H. Evangelista, R. Van Grieken, and A. F. L. Godoi, "Indoor air quality of a museum in a subtropical climate: The Oscar Niemeyer museum in Curitiba, Brazil," Sci. Total Environ., vol. 452-453, pp. 314-320, 2013.

[24] F. Lamonaca, G. Pizzuti, N. Arcuri, A. M. Palermo, and R. Morello, "Monitoring of environmental parameters and pollution by fungal spores in the National Gallery of Cosenza: A case of study," Meas. J. Int. Meas. Confed., vol. 47, no. 1, pp. 1001-1007, 2014.

[25] D. Saraga, S. Pateraki, A. Papadopoulos, C. Vasilakos, and T. Maggos, "Studying the indoor air quality in three non-residential environments of different use: A museum, a printery industry and an office," Build. Environ., vol. 46, no. 11, pp. 2333-2341, Nov. 2011.

[26] A. Worobiec, L. Samek, A. Krata, K. Van Meel, B. Krupinska, E. Anna Stefaniak, P. Karaszkiewicz, and R. Van Grieken, "Transport and deposition of airborne pollutants in exhibition areas located in historical buildings-study in Wawel Castle Museum in Cracow, Poland," J. Cult. Herit., vol. 11, no. 3, pp. 354-359, 2010.

[27] A. Proietti, M. Panella, F. Leccese, and E. Svezia, "Dust detection and analysis in museum environment based on pattern recognition," Measurement, vol. 66, pp. 62-72, 2015.

[28] E. Esposito, S. De Vito, M. Salvato, V. Bright, R. L. Jones, and O. A. M. Popoola, "Dynamic neural network architectures for on field stochastic calibration of indicative low cost air quality sensing systems," Sensors Actuators B Chem., vol. 231, pp. 701-713, Aug. 2016

[29] E. Angelini, F. Civita, S. Corbellini, D. Fulginiti, A. Giovagnoli, S. Grassini, and M. Parvis, "Innovative monitoring campaign of the environmental conditions of the Stibbert museum in Florence," Appl. Phys. A Mater. Sci. Process., vol. 122, no. 2, pp. 1 12, 2016.

[30] S. Corbellini and M. Parvis, "Wireless sensor network architecture for remote non-invasive museum monitoring," in 2016 IEEE International Symposium on Systems Engineering (ISSE), 2016, pp. 1-7.

[31] F.-J. Diego, B. Esteban, and P. Merello, "Design of a Hybrid (Wired/Wireless) Acquisition Data System for Monitoring of Cultural Heritage Physical Parameters in Smart Cities," Sensors, vol. 15, no. 4, pp. 7246-7266, Mar. 2015.

[32] B. Sensortec, "Intelligent 9-axis absolute orientation sensor." pp. $1-106,2016$. 
[33] Alphasense, "NO-A4 Nitric Oxide Sensor." [Online]. Available: http://www.alphasense.com/WEB1213/wpcontent/uploads/2016/03/NO-A4.pdf.

[34] Alphasense, "NO2-A43F Nitrogen Dioxide Sensor.".

[35] Alphasense, "SO2-A4 Sulfur Dioxide Sensor." .

[36] World Health Organization, "WHO Air quality guidelines for particulate matter, ozone, nitrogen dioxide and sulfur dioxide: global update 2005: summary of risk assessment," Geneva World Heal. Organ., pp. 1-22, 2006.

[37] G. D'Emilia, A. Gaspari, and E. Natale, "Evaluation of aspects affecting measurement of three-axis accelerometers," Meas. J. Int. Meas. Confed., vol. 77, pp. 95-104, 2016.

[38] M.-G. Masciotta, J. C. A. Roque, L. F. Ramos, and P. B. Lourenço, "A multidisciplinary approach to assess the health state of heritage structures: The case study of the Church of
Monastery of Jerónimos in Lisbon," Constr. Build. Mater., vol. 116 pp. 169-187, Jul. 2016.

[39] P. Pachón, V. Compán, E. Rodríguez-Mayorga, and A. Sáez, "Control of structural intervention in the area of the Roman Theatre of Cadiz (Spain) by using non-destructive techniques," Constr. Build. Mater., vol. 101, pp. 572-583, Dec. 2015.

[40] L.-R. ARPA, "Rapporti Giornalieri - Comune di Roma," Rapporti Giornalieri - QUALITA' ARIA, 2017. [Online]. Available: http://www.arpalazio.net/main/aria/sci/basedati/rpgg.php?pro $\mathrm{v}=$ RMC. [Accessed: 15-Feb-2017].

[41] A. Tittarelli, A. Borgini, M. Bertoldi, E. Desaeger, A. Ruprecht, R. Stefanoni, G. Tagliabue, P. Contiero, and P. Crosignani, "Estimation of particle mass concentration in ambient air using a particle counter," Atmos. Environ., vol. 42, no. 36, pp. 8543-8548, Nov. 2008. 